\title{
Testicular Size and Male Infertility in Sudanese Patients Attending Khartoum Dermatology and Venereology Teaching Hospital
}

\author{
Marawa Ahmed Mohammed Abd Erahman', Essam Eldeen Elghazali², Mohammed Ahmed Ibrahim Ahmed ${ }^{3}$, Nahla \\ Ahmed Mohammed Abdurrahman ${ }^{4}$, Mosab Nouraldein Mohammed Hamad ${ }^{5 *}$, Nassreldeen Khalid Abdelrahman ${ }^{6}$ \\ ${ }^{1,2}$ Dermatologist, Ministry of health, Khartoum State, Sudan \\ ${ }^{3,4}$ Nile Valley University, Faculty of Medicine, Atbara, Sudan \\ ${ }^{5}$ Phylum of Medical Parasitology, Department of Medical Laboratory Sciences, Faculty of Health Science, Elsheikh Abdallah Elbadri University, \\ Berber, Sudan \\ ${ }^{6}$ University of Al Fashir - Faculty of Medical Laboratory Science, Sudan
}

DOI: $10.36348 /$ sijap.2021.v04i03.002 $\quad$ | Received: 21.02 .2021 | Accepted: 08.03.2021 | Published: 15.03 .2021

*Corresponding author: Mosab Nouraldein Mohammed Hamad

\section{Abstract}

Objective: The study is conducted to evaluate the relationship between testicular volume measured by ultrasound and sperm parameters (volume, count, motility, significant leukocyte and morphology) in Sudanese infertile males attending KDTH, andrology department. Methods: Prospective cross sectional, investigational hospital based study .A total of 100 males were investigated for this study. The testicular volumes of all subjects were measured by ultrasonography. The serial semen samples were collected by the process of masturbation after 3-5 days of ejaculatory abstinence and were analyzed by CASA according to WHO criteria 2010. Results: 74 out of 100 of patients with low Testicular volume had low motility (74\%).Correlation between testicular volume and volume of semen, sperm count, morphology and presence of significant leukocyte revealed no significant correlation. Conclusions: Testicular volume had a significant correlation with sperm motility. No significant relation between testicular volume and semen volume, sperm count and sperm morphology. Measurement of testicular volume cannot be helpful alone for assessing fertility at the initial physical examination.

Keywords: Testicular volume, Male infertility, Ultrasonography, Sudan.

Copyright () 2021 The Author(s): This is an open-access article distributed under the terms of the Creative Commons Attribution 4.0 International License (CC BY-NC 4.0) which permits unrestricted use, distribution, and reproduction in any medium for non-commercial use provided the original author and source are credited.

\section{INTRODUCTION}

Infertility is a medical problem that affects more than 80 million people worldwide [1] Infertility is one of the indicators of lacking of reproductive health. It affects a vast proportion of the world's young population (10-15\%) [2]. The inability to bear children seriously impacts the psychosocial and emotional lives of couples affected by this condition [3]. It is a threat to humans continued survival on earth [4] during the past few decades an abrupt decline in semen quality was observed [2]. A meta-analysis of 63 studies indicated almost $50 \%$ reduction in sperm count during the period 1940 to 1990 [5, 9]. Though, some other studies from Finland, Scotland and Belgium did not show such trend. Recent studies have revealed overall decrease of semen quality in the male population) WHO 2000). Irrespective of race and ethnicity infertility affects 13$18 \%$ of the human population [10-13]. Therefore, it is important to understand the basic mechanisms and factors that regulate spermatogenesis whereas; understanding role of genetic factors is also of critical importance. The examination of the infertile man comprises physical examination, semen analysis, and hormone testing and ultrasound examination. Since the seminiferous tubules comprise $75-85 \%$ of the testicular mass, testicular volume is likely to reflect spermatogenesis and semen profiles in infertile men. Testicular volume measurement methods involve the use of calipers, orchidometry or ultrasonography. Orchidometry is a conventional method that has been used for many years but the cut off testicular volume that indicates normal testicular function is not established. Some studies have concluded that the ultrasound measurement of testicular volume is more confident than orchidometry [14, 15]. Bahk et al., 2010 have showed that in a group of 20-27 years old males the mean total testicular volume was $36.5 \mathrm{ml} \mathrm{[16].}$ Bujanet al., 1989 have demonstrated that testicular volume is considered to be a reliable indicator of testicular function [17]. By Condoreli et al., 2013 the 
Marawa Ahmed et al; Sch Int J Anat Physiol, Mar., 2021; 4(3): 27-31

normal testis is $>15 \mathrm{ml}$ and abnormal testis is $<12 \mathrm{ml}$ [18]. Mbaeri et al., 2013 found a strong positive correlation between testicular volume and sperm total count, he found poor semen parameters in males with total testicular volume <26 ml [19]. Aribarg et al., 1986 studying a group of fertile Thai males found the mean total testicular volume $34.4 \mathrm{ml}$, range $(24-50 \mathrm{ml})$ [20]. The mean ultrasonic total testicular volume showed by Lenz et al., 1994 in a group of infertile males was 20.6 $\mathrm{ml}$ [21]. Based on this research, the relationships between testicular volume and semen parameters were evaluated using testicular volume as a marker for testicular fertility function.

Race differences in testicle size have also been measured (Asians $=9$ grams, Europeans $=21 \mathrm{~g}$ ). This is not just because Europeans have a slightly larger body size. The difference is too large. The difference in testicle size could mean that Whites make two times as many sperm per day as do Orientals. So far, we have no information on the relative size of Blacks [22].

Japanese and Chinese men's testicles tend to be smaller than those of Caucasian men, on average. Differences in body size make only a slight contribution to these testes weights of 24 grams for Asians, 29 to 33 grams for Caucasians, and 50 grams for Africans. Marked differences among same race Caucasians produce about twice the number of spermatozoa per day than Chinese [23].

The initial evaluation of the male patient should be rapid, noninvasive, and cost-effective, as nearly $70 \%$ of conditions that cause infertility in men can be diagnosed with history, physical examination, and hormonal and semen analysis alone. More detailed, expensive, and invasive studies can then be ordered if necessary [24].

The WHO manual 2010 criterion for semen are: the lower reference limit for semen volume is 1.5 $\mathrm{ml}$; the lower reference limit for total motility is $40 \%$; the lower reference limit for sperm concentration is 15 million spermatozoa per $\mathrm{ml}$; the lower reference limit for total sperm number is 39 million spermatozoa per ejaculate; the lower reference limit for sperm morphology is $4 \%$ [24].

Treatment options are based on the underlying etiology and range from optimizing semen production and transportation with medical therapy or surgical procedures to complex assisted reproduction techniques. Technological advancements have made conceiving a child possible with as little as one viable sperm and one egg. Although the workup was traditionally delayed until a couple was unable to conceive for 12 months. Evaluation may be initiated at the first visit in slightly older couples [24].

\section{MATERIALS AND METHODS Study Design}

This cross-sectional hospital-based study was carried out between March - December 2017 among patients attending the outpatient clinic.

\section{Study Area}

This study was conducted at KDTH, Andrology department It's estimated that the number of visitors to out-patient clinic 700 patients/day (adults and children) .The hospital located in Khartoum, Sudan.

\section{Study Population}

All infertile male patients came to hospital in the period between March to December 2017.

\section{Sample Size and Data Collection}

100 adult male patients presented with primary or secondary infertility and their age above 20 years, were agree to participate in our study after informed the consent.

\section{Scrotal Ultrasound Evaluation}

Scrotal ultrasound scans were carried out in two phases: the first with the patient in supine position (with penis resting on supra pubic region) and the second in upright position to evaluate blood reflux along the pampiniform plexus, testicular malposition, or extent of any fluid collections. Examination was conducted with linear, high-resolution, and highfrequency $(7.5-14 \mathrm{MHz})$ probe dedicated to the study of soft parts and with color Doppler for detecting slow flows and scanning surface of at least $5 \mathrm{~cm}$. The TV was calculated automatically by the ultrasonography software by applying the ellipsoid formula (length $\times$ width $\times$ thickness $\times 0.52$ ). Parenchymal echo structure was considered normal in presence of thin, densely packed and homogeneously deployed echoes. Presence of finely inhomogeneous echo pattern, weakly hypo- or hyper echogenic areas was considered expression of primary testicular disease.

\section{Semen Analysis}

Semen samples were collected by masturbation in a sterile container after 2-7 days of sexual abstinence and were transported to the laboratory within 30 minutes from ejaculation. Sperm analysis was made according to the WHO criteria by CASA. The following parameters were evaluated: color, volume, liquefaction time, $\mathrm{pH}$, density, total count, progressive motility, morphology, and leukocytes.

\section{Ethical Approve}

The ethical approve was taken from ethical committee in Sudan medical association board. Written consent obtained from administration of hospital to conduct the study. All patients were consented. 


\section{DATA ANALYSIS AND PROCESSING}

By using computer programmed SPSS version 21 , Results expressed as text and illustrated tables and figures. Chi square test used to assess the significance of difference of $\mathrm{p}$ value of $<(0.05)$ was considered statically significant.

\section{RESULTS}

This study was conducted in 100 infertile male patients in KDTH andrology department from March to December 2017. In $83 \%$ of patients the duration of infertility was $1-7$ years, $14 \%$ was $8-14$ years and $3 \%$ of them more than 14 years. Fifty four percent of study population had primary infertility and $46 \%$ had secondary infertility. In $75 \%$ of patients semen volume was $>1.5 \mathrm{ml}$ while in $25 \%$ was $<1.5 \mathrm{ml}$ (Table1).In $46 \%$ of study population sperms count were $>15 \times 10^{6}$ while in $54 \%$ of them was $<15 \times 10^{6}$ (Table1).Seventy seven percent of infertile men had abnormal morphology of sperms $(<4 \%)$ while $23 \%$ had normal morphology of sperms (>4\%) (Table1). Seventy four percent of study population had abnormal motile sperms $(<40 \%)$ while $26 \%$ had normal motility $(>40)$ (Table1). Presence of significant leukocyte $>10 \mathrm{HPF}$ was in $28 \%$ of patients (Table1).In $68 \%$ of patients the size of the right testis was abnormal $(<12 \mathrm{ml})$ while the left testis was abnormal in $66 \%$ of patients ,32\% of patients had normal size of right testis $(12-20 \mathrm{ml})$ while $34 \%$ in left testis was normal(Table2).

Significant correlation between motility of the sperms and size of the right and left testes were detected $\mathrm{p}$ value $=0.02$ (Table 1 ), and there were no any statistical significant association between other parameters of semen analysis and testicular size (Table1).

Table-1: Distribution \& Correlation between semen parameters and infertility

\begin{tabular}{|c|l|l|l|l|}
\hline$\#$ & Semen parameters & Frequency & Percent & P-value \\
\hline $\mathbf{1}$ & Volume & & & \\
& $>1.5 \mathrm{ml}$ & 75 & $75.0 \%$ & \\
& $<1.5 \mathrm{ml}$ & 25 & $25.0 \%$ & 0.62 \\
& Total & 100 & $100 \%$ & \\
\hline $\mathbf{2}$ & Count & & & \\
& $>15 \times 10^{\circ} 6$ & 46 & $46 \%$ & \\
& $<15 \times 10^{\circ} 6$ & 54 & $54 \%$ & 0.9 \\
& Total & 100 & $100 \%$ & \\
\hline $\mathbf{3}$ & Morphology & & & \\
& $>4$ & 23 & $23 \%$ & \\
& $<4$ & 77 & $77 \%$ & 0.7 \\
& Total & 100 & $100 \%$ & \\
\hline $\mathbf{4}$ & Motility & & & \\
& $>40$ & 26 & $26 \%$ & \\
& $<40$ & 74 & $74 \%$ & 0.02 \\
& Total & 100 & $100 \%$ & \\
\hline $\mathbf{5}$ & Leukocyte & & & \\
& $>10 \mathrm{HPF}$ & 28 & $28 \%$ & \\
& $<10 \mathrm{HPF}$ & 72 & $72 \%$ & 0.8 \\
& Total & 100 & $100 \%$ & \\
\hline
\end{tabular}

Table-2: Distribution \& Correlation between size of testis and infertility

\begin{tabular}{|c|l|l|l|l|}
\hline$\#$ & Parameters & Frequency & Percent & P-value \\
\hline $\mathbf{1}$ & Size of right testis & & & \\
& $<12 \mathrm{ml}$ & 68 & $68 \%$ & \\
& $12-20 \mathrm{ml}$ & 32 & $32 \%$ & 0.56 \\
& $>20 \mathrm{ml}$ & 0 & $0 \%$ & \\
& Total & 100 & $100 \%$ & \\
\hline $\mathbf{2}$ & Size of left testis & & & \\
& $<12 \mathrm{ml}$ & 66 & $66 \%$ & \\
& $12-20 \mathrm{ml}$ & 34 & $34 \%$ & 0.57 \\
& $>20 \mathrm{ml}$ & 0 & $0 \%$ & \\
& Total & 100 & $100 \%$ & \\
\hline
\end{tabular}


Marawa Ahmed et al; Sch Int J Anat Physiol, Mar., 2021; 4(3): 27-31

\section{DISCUSSION}

Evaluation of the semen is the primary investigative tool in the assessment of male fertility. Over the last few decades, there have been reports to suggest decreased human semen quality (defined as sperm density) in the general population while scrotal US has also become the primary imaging modality in the evaluation of men with reduced semen quality. The accuracy of ultrasonography is within $10 \%$ of the actual volume and is better than physical examination in detecting testicular asymmetry [25].

In this study $74 \%$ of patients of low testicular volume had low motility while in $26 \%$ of them had normal motility .This result documented significant correlation between volume of the testis and sperms motility $(\mathrm{P}$-value $=0.02$. This result same with study of kristo., et al. [26], that highly positive relationship was observed between testicular volume and sperm motility.

In correlating the semen volume to the size of the testes no significant relation was detected bilaterally in this study, this result against kristo., et al. [26] which documented significant positive correlation between total testicular volume and semen volume. This difference may be due to nutritional or environmental factors.

Our study reported that there was no statistical correlation between sperms counts and testicular volume, this result disagree with study implemented by tijani., et al. [25] testicular volume correlated with sperm density. While severe oligozoospermia $(<5$ million $/ \mathrm{ml}$ ) was associated with testicular volume of 12 $\mathrm{ml}$ or less. This is may be due to racial or environmental variation.

There was no significant association reported in this study regarding testicular volume and sperm morphology, this is inconsistent with the reports of kristo., et al. [26].

\section{Conflicts of Interest}

The authors declare that there are no conflicts of interest regarding this study.

\section{ACKNOWLEDGMENTS}

The authors wish to acknowledge Miss. Sana'a Hajo, for her help in data analysis. We are very grateful to people who participated in this study and to the staff of Khartoum Dermatology Teaching Hospital (KDTH), andrology department for their assistance.

\section{REFERENCES}

1. Ochsendorf, F. R. (2008). Sexually transmitted infections: impact on male fertility. Andrologia, 40(2), 72-75.
2. Sakar, M.N., Gul, T., Atay, A.E., Celik, Y. (2008).Comparison of hysterosalpingography and laparoscopy in the evaluation of infertile women. Saudi Med. J, 29(9):1315-1318

3. Zegers, F., Hochschild J. E., Schwarze, V., Alam, F. (2008). Infertility international encyclopedia of public health. Academic Press, U5

4. Cates, W., Farley, T.M., Rowe, P.J. (1984). Patterns of infertility in the developing world. WHO Special Programmed of Research Development and Research Training in Human Reproduction. February, 11

5. Carlsen, E., Giwercman, A., Keiding, N., Skakkebaek, N.E. (1992). Evidence for decreasing quality of semen during past 50 years. BMJ, 305:609-613. [PMC free article] [PubMed]SA, 576-587

6. Liang, X.W., Lu, W.H., Chen, Z.W., Wang, X.H., Zhao, H., Zhang, G.Y. (2008). [Changes of semen parameters in Chinese fertile men in the past 25 years] Zhonghua Nan KeXue, 14, 775-778.

7. Mukhopadhyay, D., Varghese, A. C., Pal, M., Banerjee, S. K., Bhattacharyya, A. K., Sharma, R. K., \& Agarwal, A. (2010). Semen quality and agespecific changes: a study between two decades on 3,729 male partners of couples with normal sperm count and attending an andrology laboratory for infertility-related problems in an Indian city. Fertility and sterility, 93(7), 2247-2254.

8. Feki, N. C., Abid, N., Rebai, A., Sellami, A., Ayed, B. B., Guermazi, M., ... \& Ammar, L. K. (2009). Semen quality decline among men in infertile relationships: experience over 12 years in the South of Tunisia. Journal of andrology, 30(5), 541-547.

9. Paasch, U., Salzbrunn, A., Glander, H. J., Plambeck, K., Salzbrunn, H., Grunewald, S., ... \& Jørgensen, N. (2008). Semen quality in sub- fertile range for a significant proportion of young men from the general German population: a coordinated, controlled study of 791 men from Hamburg and Leipzig. International journal of andrology, 31(2), 93-102.

10. Hull, M. G., Glazener, C. M., Kelly, N. J., Conway, D. I., Foster, P. A., Hinton, R. A., ... \& Desai, K. M. (1985). Population study of causes, treatment, and outcome of infertility. $\mathrm{Br}$ Med J (Clin Res Ed), 291(6510), 1693-1697.

11. Irvine, D. S. (1998). Epidemiology and aetiology of male infertility. Human reproduction, 13(suppl_1), 33-44.

12. Thonneau, P., Marchand, S., Tallec, A., Ferial, M. L., Ducot, B., Lansac, J., ... \& Spira, A. (1991). Incidence and main causes of infertility in a resident population (1 850 000) of three French regions (1988-1989). Human reproduction, 6(6), 811-816. 
Marawa Ahmed et al; Sch Int J Anat Physiol, Mar., 2021; 4(3): 27-31

13. Jones, H. W., \& Toner, J. P. (1993). The infertile couple. New England Journal of Medicine, 329(23), 1710-1715.

14. Sakamoto, H., Ogawa, Y., \& Yoshida, H. (2008). Relationship between testicular volume and testicular function: comparison of the Prader orchidometric and ultrasonographic measurements in patients with infertility. Asian Journal of Andrology, 10(2), 319-324.

15. Sakamoto, H., Saito, K., Oohta, M., Inoue, K., Ogawa, Y., \& Yoshida, H. (2007). Testicular volume measurement: comparison of ultrasonography, orchidometry, and water displacement. Urology, 69(1), 152-157.

16. Bahk, J. Y., Jung, J. H., Jin, L. M., \& Min, S. K. (2010). Cut-off value of testes volume in young adults and correlation among testes volume, body mass index, hormonal level, and seminal profiles. Urology, 75(6), 1318-1323.

17. Bujan, L., Mieusset, R., Mansat, A., Moatti, J. P., Mondinat, C., \& Pontonnier, F. (1989). Testicular size in infertile men: relationship to semen characteristics and hormonal blood levels. British journal of urology, 64(6), 632-637.

18. Condorelli, R., Calogero, A. E., \& La Vignera, S. (2013). Relationship between testicular volume and conventional or nonconventional sperm parameters. International Journal of Endocrinology, 2013.

19. Mbaeri, T. U., Orakwe, J. C., Nwofor, A. M. E., Oranusi, C. K., \& Mbonu, O. O. (2013).
Ultrasound measurements of testicular volume: Comparing the three common formulas with the true testicular volume determined by water displacement. African Journal of Urology, 19(2).

20. Aribarg, A., Kenkeerati, W., Vorapaiboonsak, V., Leepipatpaiboon, S., \& Farley, T. M. M. (1986). Testicular volume, semen profile and serum hormone levels in fertile Thai males. International journal of andrology, 9(3), 170-180.

21. Lenz, S., Thomsen, J. K., Giwercman, A., Hertel, N. T., Hertz, J., \& Skakkebaek, N. E. (1994). Ultrasonic texture and volume of testicles in infertile men. Human Reproduction, 9(5), 878-881.

22. Race, E. (1995). Behavior: A life history perspective. New Brunswick: Transaction Publishers.

23. Christopher Ryan, Cacilda Jethå The Prehistoric Origins of Modern Sexuality, 241.

24. Abdelrahman, M. A. M. (2017). Diagnosis of Male Infertility using Ultrasound (Doctoral dissertation, Sudan University of Science and Technology).

25. Tijani, K. H., Oyende, B. O., Awosanya, G. O., Ojewola, R. W., \& Yusuf, A. O. (2014). Assessment of testicular volume: A comparison of fertile and sub-fertile West African men. African Journal of Urology, 20(3), 136-140.

26. Kristo, A., \& Dani, E. (2014). The correlation between ultrasound testicular volume and conventional semen parameters in Albanian subfertile males. Macedonian Journal of Medical Sciences, 7(3), 464-466. 